The Egyptian Journal of Hospital Medicine (April 2019) Vol. 75 (2), Page 2218-2223

\title{
Cyanoacrylate Glue Versus Suture Fixation of Mesh in Adult Inguinal Hernioplasty \\ Hazem A. Megahed
}

Department of General Surgery, Faculty of Medicine for Boys, Al-AzharUniversity, Damietta, Egypt. E-Mail: doctor_hazem_m@yahoo.com, mobile: 00201068687477

\begin{abstract}
Background: Tissue glues have been present for over twenty years and are used in surgery for a variety of indications. Use of $\mathrm{N}$ butyl- 2-cyanoacrylate based in inguinal hernia surgery were practiced for the first time in the mid-nineties. These non-suture techniques was aimed to decrease the chronic groin pain after hernioplasty without adversely affecting the outcomes

Aim of the work: this study was designed to compare the operative outcomes of mesh fixation with glue versus that with suture. The primary objective was to compare pain in the immediate postoperative period and also to compare chronic postoperative pain.

Patients and Methods: This prospective randomized study was performed Between January 2018 and January 2019 on 40 patients with unilateral inguinal hernia for whom open hernioplasty was done in the Department of surgery, Al-Azhar University Hospital, Damietta.

Results: in the present study, there was significant difference in postoperative pain perception at 24 hours, at one week and at one month $(\mathrm{p}<0.05)$ between glue group and suture group with lesser pain perception in the glue group. After the first month the difference between the two groups was non-significant. The mean operative time which was $44.35 \mathrm{~min}$ in the glue group and $57.33 \mathrm{~min}$ in suture group showed significant difference. As regard to the postoperative complications, the postoperative hematoma, infection and seroma were lesser in glue group but the difference was not significant. There was no recurrence in both groups.

Conclusions: Cyanoacrylate glue for mesh fixation in Lichtenstein repair of adult inguinal hernia shows advantages over mesh fixation by sutures in terms of immediate and chronic post-operative pain, operative time, and postoperative complications.
\end{abstract}

Keywords: Cyanoacrylate Glue, mesh fixation, hernioplasty, inguinal hernia repair

\section{INTRODUCTION}

Repair of inguinal hernia is still one of the most commonly performed procedures allover the world (1).Many techniques are used for repair of inguinal hernia, a Lichtenstein's tension free hernioplasty firstly described in $1989^{(2)}$ and is the most widely practiced surgical technique due to its superiority to the other open techniques in many ways as better postoperative comfort than before and lower incidence of recurrence which has been decreased due to the usage of prosthetic mesh.Many studies reported that the incidence of recurrence after tension-free repair was as low as $2-5 \%$ recently ${ }^{(3,4)}$. In spite of the success of this method in inguinal hernia repair,the long-standing groin pain after hernioplasty represented a great challenge to surgeons ${ }^{(5)}$. The surgeons continue to search for the ideal repair method with the best outcome and parameters other than recurrence rate were taken into consideration to determine the effects of hernioplasty (e.g. postoperative long-standing groin pain and discomfort) (1). Several small scale modifications have been made to the classical Lichtenstein's hernioplasty technique over the years. These modifications aimed to decrease the chronic groin pain after hernioplasty without adversely affecting the outcomes. Chronic groin pain was observed in the immediate postoperative period as severe groin pain and as a persisting dragging pain in the inguinal region several months after the surgery and has been attributed to the traumatic mesh fixation (6).

The incidence of long-standing groin pain after inguinal hernioplasty is estimated to be $0.7 \%$ (4) to $62.9 \%^{(5)}$ and it can be categorized into two types, neuropathic and non-neuropathic. Neuropathic pain is due to involvement of ilioinguinal, iliohypogastric or genitofemoral nerves during surgery ${ }^{(6)}$ and can be very well prevented by careful identification and preservation of the nerves during surgery and lateralization of the nerve to prevent injury. use of lightweight meshes induce a thinner fibrotic reaction thus preventing entrapment of the nerves, also the usage of atraumatic methods for mesh fixation like tissue glues prevent the incorporation of the nerves within sutures ${ }^{(7)}$

Non-neurogenic pain is a constant dull aching pain in the inguinal region which could be due to excessive posterior wall scarring due to heavy weight mesh usage. First bite for mesh fixation is taken at the pubic tubercle. This may induce osteitis of the tubercle and a source for pain. The presence of mesh and fibrosis could be perceived as a foreign body sensation and stiffness in the inguinal region.this type of pain can be 
Cyanoacrylate Glue Versus Suture Fixation...

also prevented or even reduced by the usage of atraumatic mesh fixation as tissue glues ${ }^{(\mathbf{8})}$.

Tissue glues have been present for over twenty years and are used in surgery for a variety of indications including abdominal skin wound closure' ${ }^{(9)}$ haemostasis during liver resection ${ }^{(10)}$ and endoscopic treatment of gastro-oesophageal bleeding and varices. (11). Use of Nbutyl- 2-cyanoacrylate based adhesives (Glubran 2 - GEM Srl) and fibrin based (Tissucol/Tisseel - Baxter Healthcare) in inguinal hernia surgery were practiced for the first time in the mid-nineties. $(12,13)$

Fibrin sealant which is a sealant with local hemostatic and adhesive properties consists of fibrinogen and thrombin. It has been used in the United States as a blood bank- or laboratory-derived product since the 1980s and has been commercially available since 1998.Fibrin sealant has been clinically useful in a wide variety of surgical specialties as tissue adhesive material (eg : mesh fixation), tissue sealant, hemostatic agent, drug delivery, and in tissue engineering (14).

Cyanoacrylates are a group of synthetic glues that rapidly indurate and become solid on contact with weak bases, such as water and blood. Cyanoacrylate glue can be mixed before injection with lipiodol which is oily contrast agent to slow the rate of solidification $^{(15)}$.

Cyanoacrylates form a category of substances extremely interesting for clinical applications as in hernial mesh fixation. They are synthesized in the form of monomers by condensation of a cyanoacetate compound with formaldehyde in the presence of catalysts and the adhesive film develops by fast polymerization which is triggered by hydroxyl groups on the glued surfaces ${ }^{(16)}$.

The aim of this study was to compare the operative outcomes of mesh fixation with glue versus that with suture. The primary objective was to compare pain in the immediate postoperative period and also to compare chronic postoperative pain.

\section{PATIENTS AND METHODS}

This prospective randomized study included a total of 40 patients with unilateral inguinal hernia attending at the Department of surgery, Al-Azhar University Hospital, Damietta, Egypt.Approval of the ethical committee of Al-Azhar University and a written informed consent from all the subjects were obtained. This study was conducted between January 2018 and January 2019.

Open hernioplasty was done for the 40 patients. They were randomly divided into two groups, A (20 patients) for whom mesh fixation was done by using cyanoacrylate glue and B (20 patients) for whom mesh fixed by prolene sutures.Randomization was done by even number patients for group $\mathrm{A}$ and odd number patients for group B.

The inclusion criteria were adult males with primary unilateral inguinal hernia, while exclusion criteria were patients having recurrent inguinal hernias, sliding hernia, complicated inguinal hernias, bilateral inguinal hernias, patients undergoing other concomitant abdominal surgeries, patients with coagulation disorders, patients on long term analgesics/steroid treatment and patients having connective tissue disorders.

Pain was monitored using the visual analogue scoring (VAS) scale which was done by a trained staff who was unaware of the method used (it was ranged from 0 to 10 in which zero means no pain , 1-3 means mild pain , 4-6 means moderate pain, 7-10 means severe pain). Monitoring of pain was done at 24 hours, 48 hours, 1 week, 1 month, 3 months and 6 months. Other parameters, namely, operative time in minutes and presence of hematoma, wound infection, seroma collection and recurrence rate were also monitored and recorded.

All patients underwent complete blood count, random blood glucose level,renal function tests. A complete diabetic lab if diabetic, cardiac evaluation in the presence of hypertension or cardiac conditions, chest radiograph.Abdominopelvic ultrasound to detect the prostate volume and the post void residual volume was performed in all patients to rule out benign enlargement of the prostate $(\mathrm{BPH})$ as a predisposing factor. Urologist consultation was done before operating on patients with BPH. Anesthesia consultation for patient fitness for operation was done and all the cases were performed under spinal anesthesia. The patients were put on the same basic analgesics according to VAS score for 2 days during their stay in the hospital and were discharged after 48hours. Patients were followed up for pain, hematoma,seroma, wound infections and any other complaints before and after discharge from the hospital.

\section{Surgical technique}

Alloperations were carried out under spinal anesthesia, using the same surgical technique (Lichtenstein's technique)using a polypropylene meshas a prosthetic material. An inguinal incision of 57 cmwas made 2 fingers breadth above the medial part of inguinal ligament to expose the external oblique aponeurosis. The fascia of external oblique was then divided to exposethe underlying spermatic cord and hernia. The upper and lower flaps of the external 
oblique aponeurosis were largely detached from the underlying tissues and the spermatic cord was then dissected and separated from the posterior wall of inguinal canalin order to obtain a space to allowfor subsequent placing of the mesh. In all groups particular attention was taken to identify the regional nerves and retract them away from the area of dissection to avoid their injury. In the case of indirect hernia, the hernia sac was dissected from the spermatic cord, resected and then closed with absorbable suture material. In the case of direct hernia,hernial sac reduction was done with plication of the fascia transversalis.

A $6 \times 11 \mathrm{~cm}$ polypropylene mesh was placed on the posteror wall of the inguinal canal extending from the pubic tubercle to behind the spermatic cord above the internal inguinal ring and overlapping both conjoint tendon and the shelving portion of inguinal ligament or pubic tract.
In suture group the mesh is fixed with polypropylene sutures 20 while in glue group the mesh is fixed with Cyanoacrylate Glue. The glue application is carried out through an insulin syringe or applicator to facilitate drop-wise distribution of the glue. An experienced assistant is able to apply over 20 drops. The drops of the glue were placed on the mesh, which was pressed gently against the floor of the inguinal canal.

\section{Statistical analysis}

Statistical analyses were performed by applying (SPSS, Chicago,IL,USA) and means were assessed by the usage of student's t-test A p value $\leq 0.05$ was considered statistically significant.

\section{RESULTS}

There was no significant difference as regard to age of the patient or site of the hernia (right or left) (table 1).

Table (1):Distribution of age and location of hernia between the two groups.

\begin{tabular}{|l|c|c|c|c|}
\hline \multicolumn{2}{|c|}{ Parameter } & Glue fixation & Suture fixation & $\mathrm{P}$-value \\
\hline \multicolumn{2}{|c|}{ Age in years (mean \pm SD) } & $35 \pm 8$ & $34 \pm 9$ & $\mathrm{P}=0.71$ (Non-significant) \\
\hline \multirow{2}{*}{ Location } & Right & 12 & 11 & Non-significant \\
\cline { 2 - 5 } & Left & 8 & 9 & Non-significant \\
\hline
\end{tabular}

The mean operative time which was $44.35 \mathrm{~min}$ in the glue group and $57.33 \mathrm{~min}$ in suture group showed significant difference (Table 2).

Table (2):Comparison of operative time in minutes between the two groups.

\begin{tabular}{|l|c|l|l|}
\hline Group & Mean \pm SD & p- value & Significant or not significant \\
\cline { 1 - 2 } Glue group & $\mathbf{4 4 . 3 5} \pm \mathbf{6 . 2 0}$ & $\mathrm{P}<0.0001$ & Very significant \\
\cline { 1 - 2 } Suture group & $\mathbf{5 7 . 3 3} \pm \mathbf{5 . 2 4}$ & & \\
\hline
\end{tabular}

In the present study, there was significant difference in postoperative pain perception at 24 hours, at one week and at one month $(\mathrm{p}<0.05)$ between glue group and suture group with lesser pain perception in the glue group. After the first month the difference between the two groups was non-significant (Table 3).

Table (3):Comparison of postoperative pain between the two groups.

\begin{tabular}{|l|l|l|l|l|l|l|l|}
\hline $\begin{array}{l}\text { Degree of } \\
\text { pain }\end{array}$ & $\begin{array}{l}\text { Group \& } \\
\text { p value }\end{array}$ & $24 \mathrm{hr}$ & $48 \mathrm{hr}$ & 1 week & 1 month & $\begin{array}{l}3 \\
\text { months }\end{array}$ & 6 months \\
\hline \multirow{2}{*}{$\begin{array}{l}\text { No } \\
\text { pain }\end{array}$} & Glue group & $\mathbf{2}$ & $\mathbf{1 4}$ & $\mathbf{1 8}$ & $\mathbf{2 0}$ & $\mathbf{1 9}$ & $\mathbf{1 9}$ \\
\cline { 2 - 8 } & Suture group & $\mathbf{0}$ & $\mathbf{2}$ & $\mathbf{1 0}$ & $\mathbf{1 4}$ & $\mathbf{1 7}$ & $\mathbf{1 7}$ \\
\cline { 2 - 8 } & $\mathbf{p}$ value & $\mathbf{N S}$ & $\mathbf{S}(\mathbf{p}<\mathbf{0 . 0 5})$ & $\mathbf{S}(\mathbf{p}<\mathbf{0 . 0 5})$ & $\mathbf{S}(\mathbf{p}<\mathbf{0 . 0 5})$ & $\mathbf{N S}$ & $\mathbf{N S}$ \\
\hline \multirow{2}{*}{$\begin{array}{l}\text { Mild } \\
\text { pain }\end{array}$} & Glue group & $\mathbf{1 4}$ & $\mathbf{5}$ & $\mathbf{2}$ & $\mathbf{0}$ & $\mathbf{0}$ & $\mathbf{0}$ \\
\cline { 2 - 9 } & Suture group & $\mathbf{5}$ & $\mathbf{1 0}$ & $\mathbf{8}$ & $\mathbf{6}$ & $\mathbf{3}$ & $\mathbf{3}$ \\
\cline { 2 - 9 } & p value & $\mathbf{S}(\mathbf{p}<\mathbf{0 . 0 5})$ & $\mathbf{S}(\mathbf{p}<\mathbf{0 . 0 5})$ & $\mathbf{S}(\mathbf{p}<\mathbf{0 . 0 5})$ & $\mathbf{S}(\mathbf{p}<\mathbf{0 . 0 5})$ & $\mathbf{N S}$ & $\mathbf{N S}$ \\
\hline \multirow{2}{*}{$\begin{array}{l}\text { Moderate } \\
\text { pain }\end{array}$} & Glue group & $\mathbf{4}$ & $\mathbf{1}$ & $\mathbf{0}$ & $\mathbf{0}$ & $\mathbf{0}$ & $\mathbf{0}$ \\
\cline { 2 - 8 } & Suture group & $\mathbf{1 5}$ & $\mathbf{8}$ & $\mathbf{2}$ & $\mathbf{0}$ & $\mathbf{0}$ & $\mathbf{0}$ \\
\cline { 2 - 8 } & p value & $\mathbf{S}$ & $\mathbf{S}$ & $\mathbf{N S}$ & - & - & - \\
\hline
\end{tabular}

$\mathbf{S}$ means significant $(\mathrm{p}<0.05)$ while $\mathbf{N S}$ means non-significant $(\mathrm{p}>0.05)$ relationship between the two groups

As regard to the postoperative complications in the present study, the postoperative hematoma, infection and seroma were lesser in glue group but the difference was not significant. There was no recurrence in both groups (table4). 
Cyanoacrylate Glue Versus Suture Fixation...

Table (4): Comparison of postoperative complications between the two groups.

\begin{tabular}{|l|l|l|l|l|l|}
\hline Variable & Hematoma & Infection & Seroma & Long-standing groin pain & Recurrence \\
\hline Glue group & $0(0 \%)$ & $0(0 \%)$ & $0(0 \%)$ & $1(5 \%)$ & 0 \\
\hline Suture group & $1(5 \%)$ & $1(5 \%)$ & $2(10 \%)$ & $3(15 \%)$ & 0 \\
\hline
\end{tabular}

\section{DISCUSSION}

The study conducted by Negro et al. showed that there is a significant difference in the pain experienced in the immediate postoperative period between the tissue glue group and the suture group, with the suture group experiencing a higher pain. Negro et al. also stated that the difference in pain between both the groups disappeared after 1 month. However, they observed complications like hematoma formation and ecchymoses in the glue group ${ }^{(17)}$.

Tebalaet al. in their study have found that the pain from 48 hours to 1 month (immediate postoperative pain) post-surgery was lower in the glue group as compared to suture.However, no significant difference could be appreciated between the 2 methods in terms of chronic pain after the first month ${ }^{(\mathbf{1 8})}$.

Silvestro et al. have found significant difference in the pain up to 6 months with applying of tissue adhesive ,however they have not found any difference in the pain in both groups after 6 months ${ }^{(19)}$.

Fuchs et al.have also found that although there was a significantly lower pain in the immediate postoperative period, there was no difference in the pain at 5 years post- operative period with glue mesh fixation ${ }^{(20)}$.

Goeda et al. performed a meta-analysis which showed that the operation time was significantly shorter with the use of glue if compared to suture and so is the immediate and long standing pain which is lower in the glue group ${ }^{(21)}$. In the present study, there was significant difference in postoperative pain perception at 24 hours ,at one week and at one month $(\mathrm{p}<0.05)$ between glue group and suture group with lesser pain perception in the glue group. After the first month the difference between the two groups was non-significant. These results are agreeing with the results of above studies of Negro $\boldsymbol{e t}$ $a l^{(17)}$,Tebala et $a l^{(18)}$, Silvestro et $a l^{(19)}$.,Fuchs et $a l^{(20)}$. And Goeda et al. ${ }^{(21)}$.

The present study is agreeing also with the study of Quyn et al. that have found a significantly lesser acute and long standing with glue usage in their study ${ }^{(22)}$ and with Sun et al. who recorded similar results- lesser acute and chronic post- operative pain with glue ${ }^{(23)}$.

Jeyakumar $\boldsymbol{e t}$ al. found that the operative time is shorter with glue if compared to the suture mesh fixation method, the post-operative pain upto three months was also significantly lower in the glue mesh fixation patients, Pain at different time intervals in the immediate post-operative period have all been observed to be significantly lower in the glue group. It is also found that there is a significantly higher pain (chronic groin pain) after 3 months with suture mesh fixation who needed analgesics to deal with the pain ${ }^{(8)}$.

Ashirwad Karigoudar and his colleagues conducted a prospective study using fibrin glue for mesh fixation in the Lichtenstein method of open inguinal hernia repair. They found that the use of fibrin glue for mesh fixation significantly decreases postoperative pain as evidenced by the marked difference in the mean visual analogue pain scale score of the two groups. The pain perceptions were significantly higher in the suture group as compared to the fibrin glue group ( $\mathrm{p}$ value $<0.001)$. The duration of surgery was significantly shorter in the fibrin glue group as compared to the suture group $(\mathrm{p}=0.001)$, thus making fibrin glue the safe and suitable alternative to Prolene suture for mesh fixation in open inguinal hernia repair ${ }^{(24)}$.

A meta- analysis and systemic review done by Hugh et al., have shown a significantly lower immediate and chronic pain following surgery for inguinal hernia using glue. The operative time has also been found to be significantly lower ${ }^{(25)}$.

The present study is agreeing with the results of Ashirwad Karigoudar and his colleagues, Goeda et al. and Hugh et al. as regard to the immediate and long standing pain which is lower in the glue group and also as regard to the mean operative time which was 44.35 min in the glue group and $57.33 \mathrm{~min}$ in suture group and this difference was significant.

As regard to the postoperative complications in the present study, the postoperative hematoma, infection and seroma were lesser in glue group but the difference was not significant. There was no recurrence in both groups.

Negro et al. performed a multicenter prospective observational study compared fibrin glue versus sutures for mesh fixation in the Lichtenstein repair of inguinal hernia,they showed that Patients in the fibrin glue group were also less likely to experience early local hemorrhagic complications (as ecchymosis, hematoma) than patients in the suture group ${ }^{(17)}$.

Colvin and his colleagues conducted a systematic review and meta-analysis in the year 2013, they have demonstrated that acute postoperative pain ,hematoma and time taken to return to normal activities 
were reduced when glue is used for mesh fixation. There were no differences between suture and glue fixation of mesh in terms of hernia recurrence, postoperative seroma formation, infections, numbness, operative time, duration of hospital stay, or complications requiring further surgery $(16,20,26,27,28)$.

A controlled study was done by Hidalgo and his colleagues to compare mesh fixation using fibrin sealant versus mesh fixation using sutures in 55 patients for bilateral hernioplasty, in whom mesh was fixed with glue on the left side hernia and with sutures on the right side hernia. Similar results were observed in both sides of hernia (right and left), but there was lesser post-operative pain and less inflammatory reaction associated with fibrin-fixed hernia repairs. Two patients complained of pubic pain at 6 months, but were free of pain by 12 months; no other early or late complications were observed $^{(29)}$.

In an uncontrolled study, Canonico et al. assessed the usage of fibrin sealant in 80 patients for whom sutureless Lichtenstein repair of primary unilateral hernia was done with Tissucol as a mesh fixing method. At 12 months they observed Less numbness and groin discomfort in the Tissucol versus sutures group $(\mathrm{P}=$ $0.019 ; \mathrm{P}=0.049)$; only $3 / 316$ patients $(0.94 \%)$ recurrence rate (one done byTissucol, two done by sutures) ${ }^{(30)}$.

Fortelny $\boldsymbol{e t}$ al. showed that lesser postoperative pain was observed when the mesh is fixed with fibrin sealant than that with sutures, at 6 weeks $(\mathrm{p}=0.035), 6$ months $\quad(\mathrm{p}=0.023)$, and 1 year $\quad(\mathrm{p}=0.011)$ postoperatively. Also there were a better postoperative quality of life, a shorter operative time, and a shorter hospital stay in the fibrin glue group ${ }^{(31)}$.

The study done by Liu et al. also recordedthat longstanding pain in the fibrin glue group had a lower incidence $^{(34)}$.

A systematic review of twelve randomized control trials which contained 1,992 primary inguinal hernia repairs assessing mesh fixation was done in the year 2014 by Sanders and Waydia. There was no significant variant as regard to recurrence or postoperative infection rates between fixation methods ${ }^{(33)}$.

In the year 2015,Huihui Liu and his colleagues performed a meta-analysis of nine trials on the use of fibrin glue for the open inguinal hernia repair, it was concluded that the usage of fibrin glue resulted in reduction ofthe risk of postoperative chronic groin pain. Although two studies reported a significant increase in recurrences, the pooled data did rule out this concern $(\mathbf{4 , 3 4 , 3 5 )}$. Another three trials reported significantly lower rates of chronic pain with fibrin sealant or glue fixation compared to sutures ${ }^{(\mathbf{2 6 , 3 4 )}}$ Another four studies reported lower pain rates within the first week with non-suture fixation techniques compared to suture fixation $(\mathbf{2 6 , 3 4 )}$

The results of the above studies are similar to the results of the present study except for the meta-analysis of Huihui and his colleagues which reported a significant increase in recurrences in the glue group in two studies of nine trials ${ }^{(\mathbf{4})}$.

\section{CONCLUSION}

It could be concluded that cyanoacrylate glue for mesh fixation in Lichtenstein repair of adult inguinal hernia shows advantages over mesh fixation by sutures in terms of immediate and chronic post-operative pain, operative time, and postoperative complications.

\section{REFERENCES}

1.Junsheng Li, Zhenling Ji, Tao C (2012): Comparison of open preperitoneal and Lichtenstein repair for inguinal hernia repair: a meta-analysis of randomized controlled trials. The American Journal of Surgery ,204 (5): 769-778

2. Amid P (2004): Lichtenstein tension-free hernioplasty: its inception, evolution and principles. Hernia,8 (1):1-7.

3.Amid PK, Shulman AG, Lichtenstein IL (1996): Open 'tension-free' repair of inguinal hernias: the Lichtenstein technique. Eur J Surg., 162: 447-453.

4.Huihui L, Xiao Z, YanG,Shanyu G (2015): Meta-Analysis Examining the Use of Fibrin Glue Mesh Fixation versus Suture Mesh Fixation in Open Inguinal Hernia Repair, Dig Surg.,31:444-451.

5.Kurzer M, Belsham PA, KarkA E (2003): The Lichtenstein repair for groin hernias. SurgClin N Am., 83:1099-1117.

6.Ladwa N, Sajid M, Sains P, Baig M (2013): Suture mesh fixation versus glue mesh fixation in open inguinal hernia repair: a systematic review and meta-analysis. Int J Surg., 11 (2):128-35.

7.Loos M, Roumen R, Scheltinga M (2007):Classifyingpostherniorrhaphy pain syndromes following elective inguinal hernia repair. World J Surg.,31 (9):1760-1765.

8.Jeyakumar S, Tharun G, Shruthi C (2018): Glue versus suture for mesh fixation in open inguinal hernia repair, IntSurg J.,5 (4):1443-1448.

9.Keng TM, Bucknall TE (1987): A clinical trial of tissue adhesive (histoacryl) in skin closure of groin wounds. Med J Malaysia, 44: 122-128.

10.Chapman WC, Clavien P, Fung JJ, Block JE (2001): Managing hepatic bleeding with autologous plasma/collagen- based fibrin sealant. Arch Surg.,136 (8):967.

11. Dhiman RK, Chawla Y, Taneja S, Biswas R, Sharma TR, Dilawari JB (2002): Endoscopic sclerotherapy of gastric variceal bleeding with N-butyl-2-cyanoacrylate. J ClinGastroenterol.,35 (3):222-227.

12.Farouk R, Drew PJ, Qureshi A, Roberts AC, Duthie GS, Monson JR (1996): Preliminary experience with butyl-2cyanoacrylate adhesive in tension-free inguinal hernia repair. Br J Surg., 83:1100. 
13. Canonico S, Sciaudone G, Pacifico F, Santoriello A (1999):Inguinal hernia repair in patients with coagulation problems: prevention of postoperative bleeding with human fibrin glue. Surgery, 125:315-317.

14 .Paola L, Silvia B, and Dario S (2010): Cyanoacrylate surgical glue as an alternative to suture threads for mesh fixation in hernia repair. Journal of Surgical Research, 163 (2): $5-8$.

15.Seewald S, Sriram P, Nagra $M$ et al. (2002): The expert approach: cyanoacrylate glue in gastric variceal bleeding. Endoscopy,34:926-932.

16.Birch DW, Park A (2001):Octylcyanoacrylate tissue adhesive as an alternative to mechanical fixation of expanded polytetrafluoroethylene prosthesis. Am Surg.,67:974.

17.Negro P, Basile F, Brescia A, BuonannoG,Campanelli G, Canonico S et al. (2010): Open tension-free Lichtenstein repair of inguinal hernia: use of fibrin glue versus sutures for mesh fixation.Hernia,15 (1):714.

18.Tebala G (2015): Cyanoacrylate glue versus suture fixation of mesh in inguinal hernia open repair: a randomized controlled clinical trial. Gastroenterol Hepatol.,2 (5):2-7.

19 .Canonico S, Benevento R, Perna G, Guerniero R, Sciaudone G, Pellino G et al. (2013): Sutureless fixation with fibrin glue of lightweight mesh in open inguinal hernia repair: Effect on postoperative pain: A double-blind, randomized trial versus standard heavyweight mesh. Surg.,153 (1):126-30.

20.Kim-Fuchs C, Angst E, Vorburger S, Helbling C, Candinas D, Schlumpf R (2011):Prospective randomized trial comparing sutured with sutureless mesh fixation for Lichtenstein hernia repair: long-term results. Hernia,16 (1):21-7.

21.deGoede B, Klitsie $P$, van Kempen B, Timmermans $L$, Jeekel J, Kazemier G et al. (2013): Meta-analysis of glue versus sutured mesh fixation for Lichtenstein inguinal hernia repair. Br J Surg.,100 (6):735-42.

22.Quyn AJ, Weatherhead KM, Daniel T (2012): Chronic pain after open inguinal hernia surgery: suture fixation versus self-adhesive mesh repair. Langenbeck's Arch Surg.,397 (8):1215-8.

23.Sun P, Cheng X, Deng S, Hu Q, Sun Y, Zheng Q (2017): Mesh fixation with glue versus suture for chronic pain and recurrence in Lichtenstein inguinal hernioplasty. Cochrane Database Syst Rev.,2:1-72.

24.Ashirwad K,ArunK,SourabhM,Nikhil G, Durga C (2016): A Prospective Randomized Study Comparing Fibrin Glue Versus Prolene Suture forMesh Fixation in Lichtenstein Inguinal HerniaRepair, Indian J Surg., 78 (4):288-292.
25.Ergönenç T, Beyaz S, Özocak H, Palabıyık O, Altıntoprak F (2017): Persistent post-herniorrhaphy pain following inguinal hernia repair: a cross-sectional study of prevalence, pain characteristics, and effects on quality of life. Int J Surg.,46:126-32.

26.Shen YM, Sun WB, Chen J, Liu SJ, Wang MG (2012) :NBCA medical adhesive (n-butyl-2 cyanoacrylate) versus suture for patch fixation in Lichtenstein inguinal herniorrhaphy: a randomized controlled trial. Surgery ,151 (4):550-555.

27.Colvin H, Rao A, Cavali M, Campanelli G, Amin A (2013): Glue Versus Suture Fixation of Mesh During Open Repair of Inguinal Hernias: A Systematic Review and Meta-analysis. World Journal of Surgery, 37 (10): 22822292.

28.Dabrowiecki S, Pierscinski S, Szczesny W (2012):Glubran 2 glue for mesh fixation in Lichtenstein's hernia repair: a double-blind randomized study. WideochirInne Tech MaloInwazyjne,7: 96-104.

29.Hidalgo M, Castillo MJ, Eymar JL, Hidalgo A (2005): Lichtenstein inguinal hernioplasty: sutures versus glue. Hernia, 9:242-244.

30.Canonico S, Santoriello A, Campitiello F, Fattopace A, Corte AD, Sordelli I, Benevento R (2005): Mesh fixation with human fibrin glue (Tissucol) in open tension-free inguinal hernia repair: a preliminary report. Hernia ,9:330333.

31.Fortelny RH, Petter-Puchner AH, Redl H, May C, Pospischil W, Glaser K (2014): Assessment of pain and quality of life in Lichtenstein hernia repair using a new monofilament PTFE mesh: comparison of suture vs fibrinsealant mesh fixation. Front Surg.,(1):45.

32.Liu H, Zheng X, Gu Y, Guo S (2014): A meta-analysis examining the use of fibrin glue mesh fixation versus suture mesh fixation in open inguinal hernia repair. Dig Surg.,31 (6):444-51.

33.Sanders DL, Waydia S (2014): A systematic review of randomized control trials assessing mesh fixation in open inguinal hernia repair. Hernia ,18 (2):165-76.

34.Campanelli G, Pascual MH, Hoeferlin A, Rosenberg J, Champault G, Kingsnorth A, Miserez M (2012): Randomized, controlled, blinded trial of Tisseel/Tissucol for mesh fixation in patients undergoing Lichtenstein technique for primary inguinal hernia repair: results of the TIMELI trial. Ann Surg. , 255: 650-657.

35.Bracale U, Rovani M, Picardo A, Merola G, Pignata G, Sodo M, Di Salvo E, Ratto EL, Noceti A, Melillo P (2014): Beneficial effects of fibrin glue (Quixil) versus Lichtenstein conventional technique in inguinal hernia repair: a randomized clinical trial. Hernia, 18: 185-192. 